\title{
Exploring Polymer-Modified Concrete and Cementitious Coating with High-Durability for Roadside Structures in Xinjiang, China
}

\author{
Yinchuan Guo, ${ }^{1}$ Aiqin Shen, ${ }^{1}$ and Xiaohui Sun ${ }^{2}$ \\ ${ }^{1}$ Key Laboratory of Highway Engineering in Special Region of Ministry of Education, Changan University, \\ Xian, Shaanxi 710064, China \\ ${ }^{2}$ Louisiana Transportation Research Center, 4101 Gourrier Avenue, Baton Rouge, LA 70808, USA
}

Correspondence should be addressed to Yinchuan Guo; silver007007@163.com

Received 24 February 2017; Accepted 18 April 2017; Published 14 May 2017

Academic Editor: Giorgio Pia

Copyright (c) 2017 Yinchuan Guo et al. This is an open access article distributed under the Creative Commons Attribution License, which permits unrestricted use, distribution, and reproduction in any medium, provided the original work is properly cited.

\begin{abstract}
The concrete roadside structures in Xinjiang, China, such as roadside barriers, bridge rails, and drainage holes, are severely damaged by the coupled effect of seasonal freeze-thaw cycles and deicer salts. To solve the corrosion problems of roadside structures, polymermodified concrete was recommended for the future construction of roadside structures and polymer-modified cementitious coating was suggested for the protection of the current corroded ones. In this study, air-entraining agent and carboxylated styrene-butadiene latex were added for concrete modification and the corresponding performance tests were conducted. In addition, the performances of six types of readily available coating materials, including the acrylic latex modified cementitious coating designed in this study, were tested in freeze-thaw condition with the presence of chloride ions. The results show that $0.013 \%$ of the air-entraining agent and $10 \%$ of the carboxylated styrene-butadiene latex were appropriate dosage rates for the modification of Portland cement concrete, in terms of the improvement of the freeze-thaw resistance, compressive strength, and chloride impermeability. For the protection of the current corroded roadside structures, the acrylic-modified cementitious coating material demonstrated a good performance and the field monitoring confirmed that the coating is suitable for the protection of the roadside structures in Xinjiang.
\end{abstract}

\section{Introduction}

In Xinjiang, a province in northwest China, the highway concrete roadside structures, such as roadside barriers, bridge rails, and drainage holes, are severely damaged by the coupled effect of seasonal freeze-thaw cycles and the application of deicer salts (commonly sodium chlorides). Figure 1 demonstrates the corrosions of these roadside structures in Xinjiang. Due to the existence of the drainage gradient on pavement, these roadside structures are exposed to the deicer salts even longer as compared with the pavement surface and therefore the damage is usually more severe. The corrosion of roadside structures not only threatens the traffic safety on the highway but also influences the serviceable life of infrastructures. Thus, it is urgent to prevent the further corrosion of the roadside structures and necessary to improve the durability of newly constructed roadside structures.
The durability of the concrete structure is the ability to last a long time without significant deterioration, which includes the resistances to freeze-thaw cycle, corrosive solution, and abrasion [1]. To improve the durability of the concrete structure, numerous studies have been carried out in the last several decades $[2,3]$. Polymer modification is one of the most effective methods to enhance the performance of Portland concrete $[4,5]$. The polymer modifications to cement concrete were implemented through adding polymer latex, dispersible polymer powder, a water-soluble polymer, or liquid polymer into the cement mortar [6]. Development of polymer films within the microstructure of cement concrete was considered as the primary mechanism of performance improvement [7, 8]. Polymer film and hydrates products develop an interactive network firmly holding aggregates together, thus improving the strength and abrasion resistance 


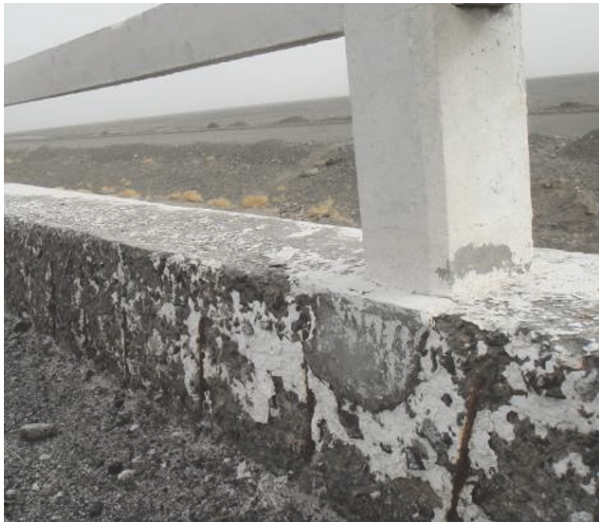

(a) Corroded bridge rail

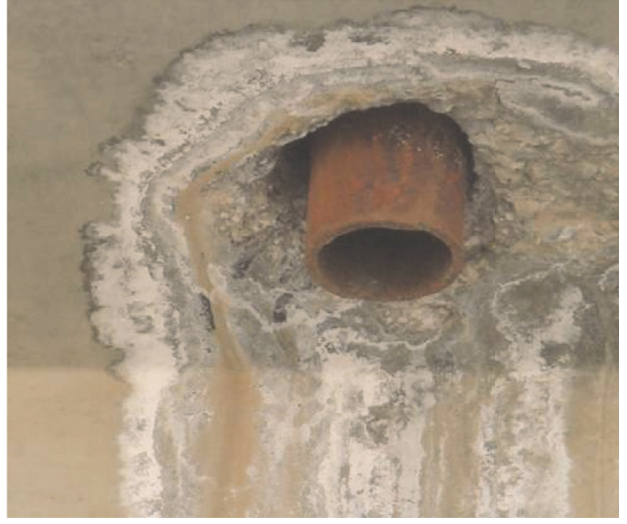

(b) Corroded drainage hole

FIGURE 1: Corrosion of roadside structures in Xinjiang.

and reducing the permeability $[9,10]$. In addition to the application of the polymer-modified concrete, polymer coating or polymer-modified cementitious coating is another feasible technique to improve the durability of the Portland cement concrete. The polymer-modified cementitious coating can prevent the penetration of chlorides and water into the concrete and therefore improve the durability of concrete structures in freeze-thaw condition.

The durability of concrete can be evaluated through corresponding performance tests which simulate the field conditions, such as freeze-thaw resistance test [11], chloride ion permeability $(\mathrm{CP})$ test [12], and water absorption test [5, 12]. Further to the performance testing, the micromechanism of polymer modification could be observed through mercury intrusion porosimetry (MIP) test [6] and scanning electron microscopy (SEM) [7]. It was concluded that the performance of cement paste and concrete is highly related to the pore volume and pore size distribution. Generally, large capillaries (larger than $100 \mathrm{~nm}$ ) affect the strength and permeability of concrete $[13,14]$ while small capillaries (less than $100 \mathrm{~nm}$ ) influence the shrinkage and creep behavior of concrete [1517].

To solve the corrosion problems of roadside structures in Xinjiang, polymer-modified concrete was recommended for the future construction of roadside structures and polymermodified cementitious coating was suggested for the protection of the current corroded roadside structures. However, the dosage rate and the type of polymers need to be further investigated.

In this study, to explore high-durability concrete for the future construction of the roadside structures, air-entraining agent and carboxylated styrene-butadiene latex were added for the modification of Portland cement concrete and the corresponding performance tests were conducted, including freeze-thaw tests, compressive strength tests, and chloride ion permeability tests. The micromechanism of polymer modification was further investigated by the mercury penetration test. In addition, the performances of six types of coating materials, including the acrylic latex modified cementitious coating designed in this study, were compared in freezethaw condition with the presence of chlorides so that a bestperformed coating material can be selected for the protection of the corroded roadside structures in Xinjiang. The acrylic latex modified cementitious coating material in this study was implemented in Xinjiang and its performance was monitored for three years. Figure 2 shows the flow chart of this study.

\section{Materials and Experimental Design}

\subsection{Materials}

2.1.1. Portland Cement Concrete. In this study, type 325 Portland cement (the compressive strength of cement mortar at 28 days is greater than $32.5 \mathrm{MPa}$ ), natural sand with an apparent gravity of $2.56 \mathrm{~g} / \mathrm{cm}^{3}$, and natural gravel with an apparent gravity of $2.68 \mathrm{~g} / \mathrm{cm}^{3}$ were used to prepare specimens for testing. Figure 1 shows the gradation of the mixture of the sand and gravel used in this study. As shown in Figure 3, the gradation curve located within the lower and upper limits defined by JTG E30-2005 [18].

2.1.2. Air Entraining Agent. A rosin-based air-entraining agent which is readily available in the local market was chosen as the additive of the Portland cement concrete to improve its durability in freeze-thaw cycles. Table 1 shows the properties of the air-entraining agent.

2.1.3. Polymer. To improve the durability of the newly constructed roadside structures, carboxylated styrene-butadiene latex was chosen as the modifier of the Portland cement concrete due to its improvement in mechanical properties and water tightness. To explore the polymer-modified cementitious coating for the current corroded structures, acrylic latex, which is a coating material with excellent water tightness, was chosen and mixed with cement and sand to prepare the coating materials. The properties of carboxylated styrene-butadiene latex and acrylic latex are listed in Table 2. 


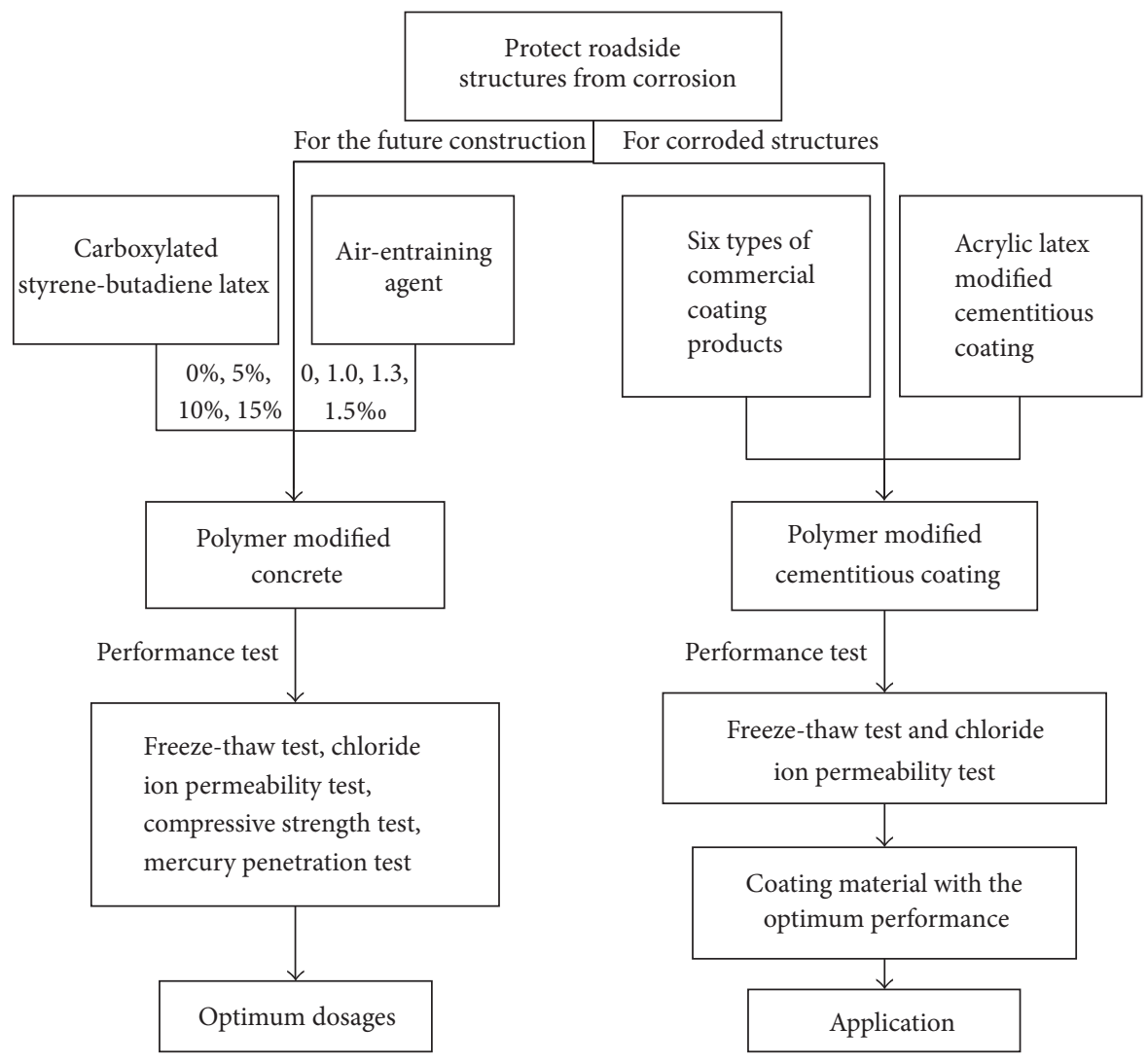

FIGURE 2: Flow chart of this study.

TABLE 1: Properties of the air entraining agent.

\begin{tabular}{lccccc}
\hline $\mathrm{pH}$ & Solid content (\%) & Water-reducing rate (\%) & Air-content rate (\%) & Density $(\mathrm{g} / \mathrm{ml})$ & Color \\
\hline $8-9$ & $57-60$ & 6 & $3.5-5.5$ & $1.04 \pm 0.01$ & Deep brown \\
\hline
\end{tabular}

2.1.4. Coating. Six types of coatings that are readily available in the local market were used in this study:

(1) Acrylate copolymer-modified cement-based coating, $\mathrm{C} 1$.

(2) Two-component polyurethane coating, C2.

(3) Acrylic ester coating, C3.

(4) Cementitious capillary crystalline coating, C4.

(5) Silicone hydrophobic agent, C5.

(6) Acrylic latex modified cementitious mortar specifically designed in this study, C6.

The coatings, $\mathrm{C} 1-\mathrm{C} 5$, were commercial products and readily available in the markets. C6 was specifically designed in this study for the protection of the roadside structure in Xinjiang to obtain a high-performance and cost-effective coating material. The composition of C6 is shown in Table 3. The thickness of the surface coating was controlled in $3 \mathrm{~mm}$ to $5 \mathrm{~mm}$.

2.2. Concrete Mix Design. In total, eight types of concrete mixes were prepared, as shown in Table 4. H0, H1, H2, and H3

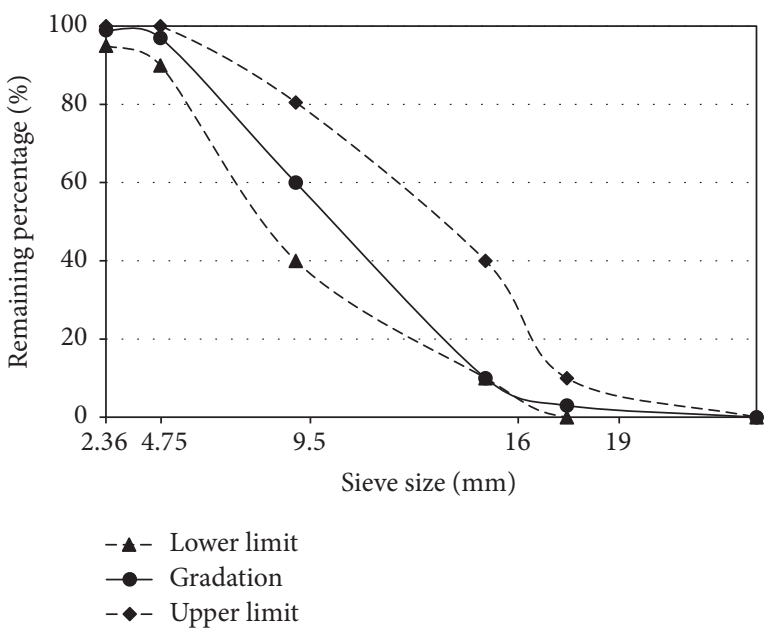

FIGURE 3: Gradation of the mixture of gravels and sands.

as shown in Table 4 were aimed at investigating an appropriate content of the air-entraining agent to improve the durability of the concrete. Mix type H0 was used to prepare samples 
TABLE 2: Properties of polymers.

\begin{tabular}{|c|c|c|}
\hline Properties & $\begin{array}{c}\text { Carboxylated } \\
\text { styrene-butadiene } \\
\text { latex }\end{array}$ & Acrylic latex \\
\hline Solids content, \% & $51 \pm 1$ & $57 \pm 1$ \\
\hline $\mathrm{pH}$ & $7.8-10$ & $7.5-8.5$ \\
\hline Viscosity at $25^{\circ} \mathrm{C}, \mathrm{mPa} \cdot \mathrm{s}$ & $35-150$ & $140-200$ \\
\hline Density, $\mathrm{g} / \mathrm{cm}^{3}$ & 1.01 & 1.03 \\
\hline Mean diameter, nm & 0.15 & 0.2 \\
\hline
\end{tabular}

for the evaluation of the performances of various coating materials as well. J0, J1, J2, and J3 were prepared to investigate the performance of the concrete with a combined effect of the polymer modification and air entrainment. Since the polymer can significantly reduce the water/cement ratio, watercement ratios for polymer-modified mixes were reduced with the increase of the polymer content. For each type of the concrete mix, three types of concrete samples, type $1(100 \times 100 \times$ $\left.400 \mathrm{~mm}^{3}\right)$, type $2\left(150 \times 150 \times 150 \mathrm{~mm}^{3}\right)$, and type $3(\Phi 100 \times$ $50 \mathrm{~mm}^{3}$ ), were prepared for the freeze-thaw test, compressive strength test, and chloride ion permeability test, respectively.

\subsection{Test Method}

2.3.1. Freeze-Thaw Resistance Test. Freeze-thaw resistance is a primary consideration for concrete culvert design in a cold region, especially when the corrosive environment and the cold weather combine. The freeze-thaw resistance test was conducted according to JTG E30-2005 in this study. For each mix type, three concrete beam specimens were cured 24 days in curing room at a temperature of $20 \pm 2^{\circ} \mathrm{C}$, followed by a four-day immersion in a $4 \%$ sodium chloride $(\mathrm{NaCl})$ solution. To apply the freeze-thaw resistance test, specimens were placed in a freeze-thaw chamber and submerged in the $4 \% \mathrm{NaCl}$ solution. Freeze-thaw cycles were conducted on both the polymer-modified concrete specimens (300 cycles applied) and the coated ones (150 cycles applied) with the upper and lower temperature limits of $8^{\circ} \mathrm{C}$ and $-17^{\circ} \mathrm{C}$, respectively. Each freeze-thaw cycle took about 3 hours. The residual weight and dynamic modulus of each specimen, which were calculated by measuring the natural frequency, were recorded every 25 cycles. These data were used to calculate the weight loss in percentage and relative dynamic modulus in percentage. A lower weight loss or a higher relative dynamic modulus indicates a better resistance to freeze-thaw cycles.

2.3.2. Chloride Permeability Test. The tests were conducted according to JTJ275-2000 [19] using $50 \mathrm{~mm}$ in height and $100 \mathrm{~mm}$ in diameter cylindrical specimens. Three specimens that were saturated for 24 hours in water were tested for each type of concrete. After conditioning, the specimen was placed in the testing apparatus in which one end of the specimen was exposed to a solution with $3 \%$ sodium chloride $(\mathrm{NaCl})$ and the other end to a solution with $1.2 \%$ sodium hydroxide $(\mathrm{NaOH})$. A $60 \mathrm{~V}$ voltage was applied to the specimen to accelerate the penetration of chloride into the specimen. The total charge passed through the specimen within 6 hours was used for quantifying the chloride permeability of the specimen. A higher coulomb value indicates a higher permeability. Table 5 lists the detailed classification of the chloride permeability.

2.3.3. Mercury Penetration Test. In this study, the Quantachrome Autoscan 60 Mercury Porosimeter was used to measure the pore size distribution of the specimen. Mercury penetration test is based on the assumption that a nonwetting liquid, such as mercury, would only intrude capillaries under pressure and the relationship between the pressure and capillary diameter was described by Washburn's equation, which shows an inverse relationship between the intruded pore radius and the applied pressure [20].

\section{Results and Discussion}

\subsection{Exploring Polymer Modified Concrete for \\ Newly Constructed Roadside Structures}

3.1.1. Addition of the Air Entraining Agent. To improve the durability of the concrete, air-entraining agent was added to the concrete mix. The contents of the air-entraining agent in the concrete mixes, $\mathrm{H} 0, \mathrm{H} 1, \mathrm{H} 2$, and $\mathrm{H} 3$, were 0 , $0.01 \%, 0.013 \%$, and $0.015 \%$, respectively. The corresponding air entrainments, measured according to JTG E30-2005, were $1.97 \%, 5.18 \%, 6.31 \%$, and $7.43 \%$, respectively. Figure 4 shows the relative dynamic modulus (Figure 4(a)) and the percentage of scaled-off mass (Figure 4(b)) under the freezethaw test in the presence of chlorides. As shown in Figure 4, the relative dynamic modulus decreased and the scaled-off particles increased with the increase of the freeze-thaw cycles. During the freezing process, due to the volume expansion of ice lenses and crystallized $\mathrm{NaCl}$, the air voids were expanded and new cracks were created, which accelerated the penetration of the $\mathrm{NaCl}$ solution into the concrete specimens. With the additive of the air-entraining agent, the decrease of the relative dynamic modulus and the scaling off of the specimen were much slower. These results indicate that the addition of the air-entraining agent significantly retarded the deterioration of the concrete in the coupled effect of freezethaw cycles and chlorides.

In other words, the results in Figure 4 imply that the resistance of the concrete in freeze-thaw cycles was improved with the increase of the content of the air-entraining agent. However, if the addition of the air-entraining agent was too high (e.g., 0.015\%), as shown in Figure 5, the charge passed in the chloride permeability test increased substantially, which means more chlorides penetrated into the concrete. Moreover, as shown in Figure 6, the compressive strength of concrete $\mathrm{H} 3$ decreased significantly as well. After applying freeze-thaw cycles, the trend became more obvious. Therefore, based on the results in Figures 4, 5, and 6, 0.013\% was considered as an appropriate dosage for the addition of the air-entraining agent.

3.1.2. Addition of the Polymer. To improve the durability of the concrete in a further step, carboxylated styrene-butadiene latex was introduced to modify the concrete mix with the 
TABLE 3: Composition of the polymer-modified mortar.

\begin{tabular}{|c|c|c|c|c|c|}
\hline Compositions & Acrylic latex & Number 425 cement & Sand (number 100) & Sand (numbers 100-200) & Total \\
\hline Acrylic latex & 450 & 260 & 200 & 90 & 1000 \\
\hline
\end{tabular}

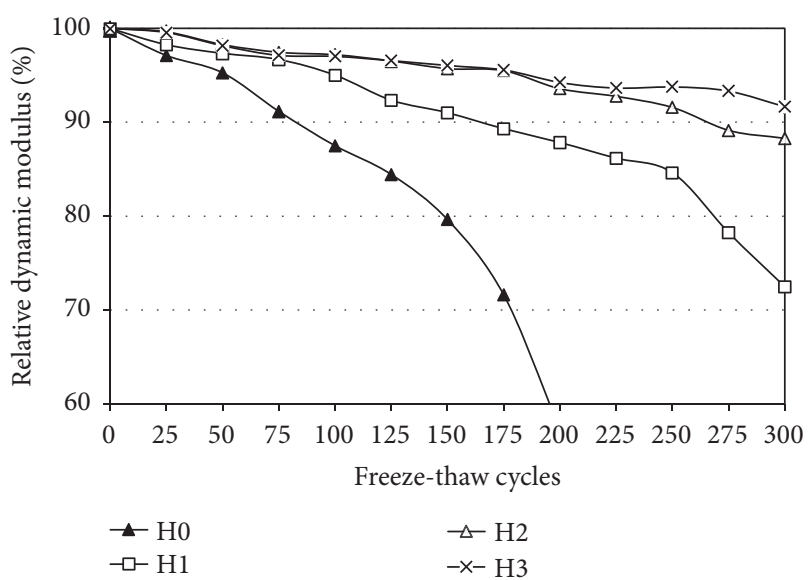

(a)

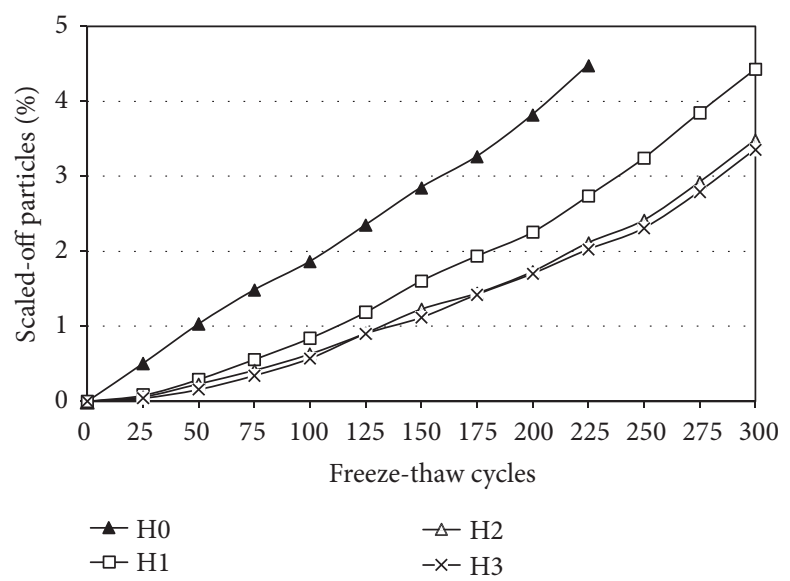

(b)

Figure 4: Portland cement concrete with dosages of air-entraining agents under freeze-thaw cycles: (a) relative dynamic modulus and (b) percentage of scaled-off mass.

TABLE 4: Concrete mix design.

\begin{tabular}{lccc}
\hline Mix type & Air entraining agent $(\%)$ & $\mathrm{p} / \mathrm{c}(\%)$ & w/c \\
\hline H0 & 0 & - & 0.41 \\
H1 & 1.0 & - & 0.41 \\
H2 & 1.3 & - & 0.41 \\
H3 & 1.5 & - & 0.41 \\
J0 & 1.3 & 0 & 0.43 \\
J1 & 1.3 & 5 & 0.33 \\
J2 & 1.3 & 10 & 0.28 \\
J3 & 1.3 & 15 & 0.24 \\
\hline
\end{tabular}

TABLE 5: Chloride penetrability.

\begin{tabular}{lc}
\hline Charge passed (Coulombs) & Chloride penetrability \\
\hline$>4000$ & High \\
2000 to 4000 & Moderate \\
1000 to 2000 & Low \\
100 to 1000 & Very low \\
$<100$ & Negligible \\
\hline
\end{tabular}

dosage $(0.013 \%)$ of the air-entraining agent. Figure 7 shows the relative dynamic modulus and the percentage of scaledoff mass under the freeze-thaw test in the presence of chlorides. In Figure 7, the polymer content of J0, J1, J2, and J3 was $0 \%, 5 \%, 10 \%$, and $15 \%$, respectively. As shown in Figure 7 , the presence of the polymer retarded the decrease of the dynamic modulus and the scaling off of the particles in the freeze-thaw cycles. By comparing Figures 4(b) and 7(b), it is found out that the mass of the scaled-off particles was reduced in a further step.

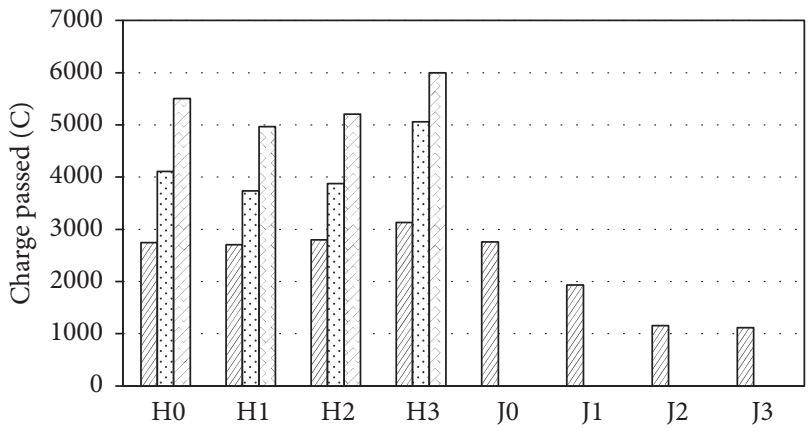

Number of freeze-thaw cycles:
$\begin{array}{ll}\square & 0 \\ \square & 25 \\ \square & 50\end{array}$

FIGURE 5: Charge passed of various types of concrete.

Chloride penetration tests were conducted on the polymer-modified concrete samples as well and the results are shown in Figure 5. It is found out that the charges passed were reduced significantly with the increase of the polymer content. The classification of the chloride permeability shifted from moderate to low according to Table 3. The result indicates that the penetration of the chlorides became sluggish with the presence of the polymer. In Figure 5, 10\% and 15\% polymer contents demonstrated similar chloride penetration performance. The decrease of the chloride penetration was mainly caused by two reasons, the polymer film that bonded with the hydration matrix and the low water-cement ratio due to the addition of the polymer [21]. 


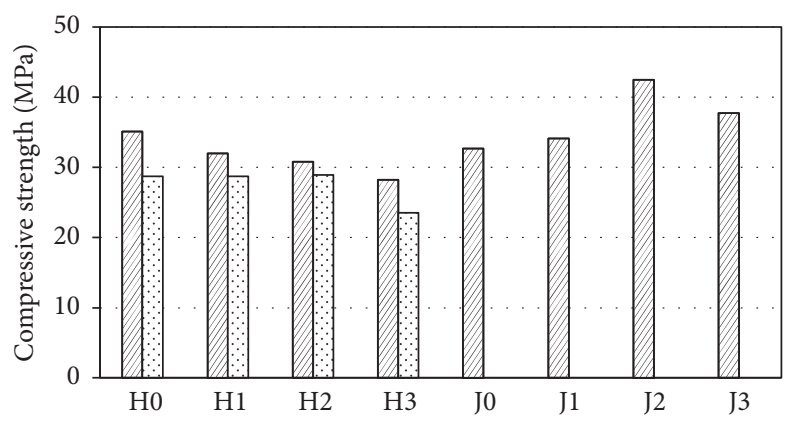

Number of freeze-thaw cycles:

$\square 0$

๑ 25

FIGURE 6: Compressive strength of various types of concrete.

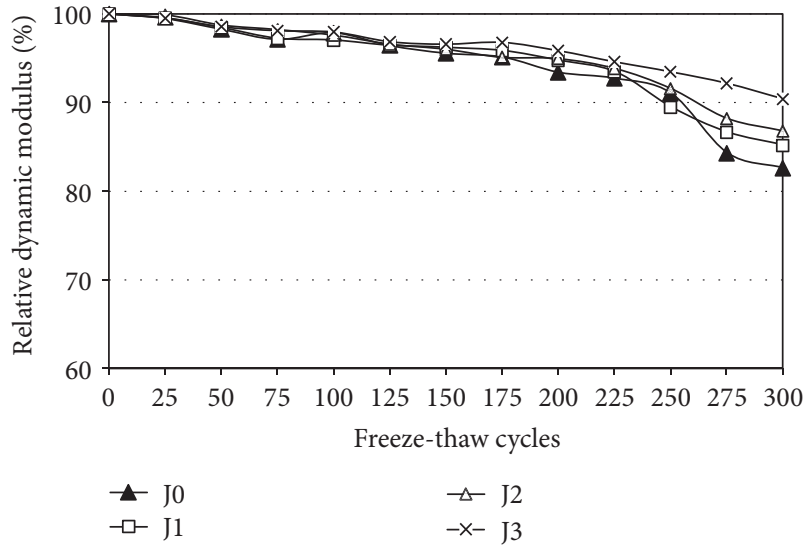

(a)

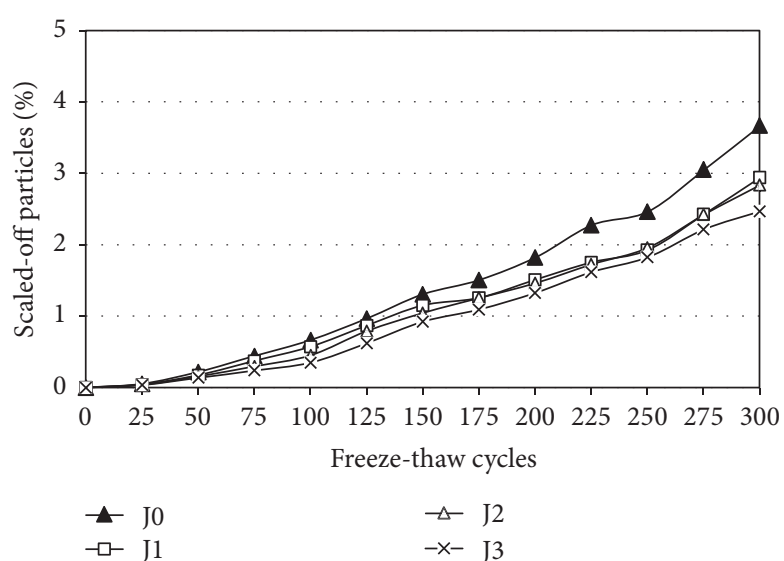

(b)

FIGURE 7: Polymer modified concrete with $0.013 \%$ of the air-entraining agent under freeze-thaw cycles: (a) relative dynamic modulus and (b) percentage of scaled-off mass.

The compressive strength of the polymer-modified concrete was shown in Figure 6. The compressive strength increased with the increase of the polymer content and the compressive strength reached its maximum value at a $10 \%$ polymer content. With a $15 \%$ polymer content, the compressive strength of the concrete did not increase but decreased significantly. The possible reason is that a higher content of the polymer partially occupied the space of the cement hydration products. Therefore, a $10 \%$ polymer content and a dosage rate of the air-entraining agent at $0.013 \%$ was chosen for the durability improvement of the cement concrete for the roadside structures in Xinjiang.

3.1.3. Pore Size Distribution. To investigate the combined effect of the air-entraining agent and the polymer, the pore size distributions of the concrete samples were obtained by the Mercury intrusion porosimetry and the results are shown in Figure 8. The peaks of pore volumes were located in the range between $10 \mathrm{~nm}$ and $50 \mathrm{~nm}$ for all the mix types. As compared with H0, J1 had more pores with the pore size less than $100 \mathrm{~nm}$. This portion of pores was mainly generated due to the presence of the air-entraining agent. With the polymer content increasing from $5 \%$ to $15 \%$, the pore volumes decreased significantly as a result of the existence of the continuous polymer film in the hydration matrix. The decrease of pores with the size larger than $100 \mathrm{~nm}$, which are considered as large capillaries and defects of the cement hydration matrix, indicates the enhancement of the durability. It is known that large capillaries dominate the durability of the cementitious material. The combined effect of the polymer and the air-entraining agent reduced the volume of large capillaries and therefore improved the overall durability.

\subsection{Surface Coating for Protecting the Current Corroded Roadside Structures}

3.2.1. Performance Testing. To prevent the further corrosion of the existing roadside structures in Xinjiang, the surface coating is an attractive alternative. The selected six types of surface coatings were applied on the concrete samples prepared with the $\mathrm{H} 0 \mathrm{mix}$. The chloride penetration of these coated samples was tested and the results are shown in Figure 9. It was found out that $\mathrm{C} 4$ and $\mathrm{C} 5$ did not perform well in terms of the charge passed while coatings $\mathrm{Cl}, \mathrm{C} 2, \mathrm{C} 3$, 


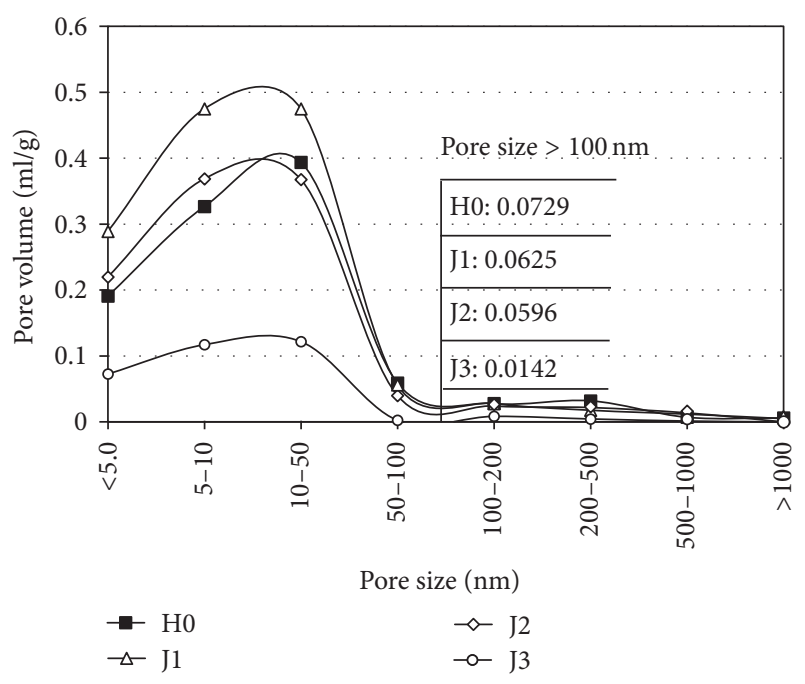

FIgURE 8: Pore size distribution in the samples.

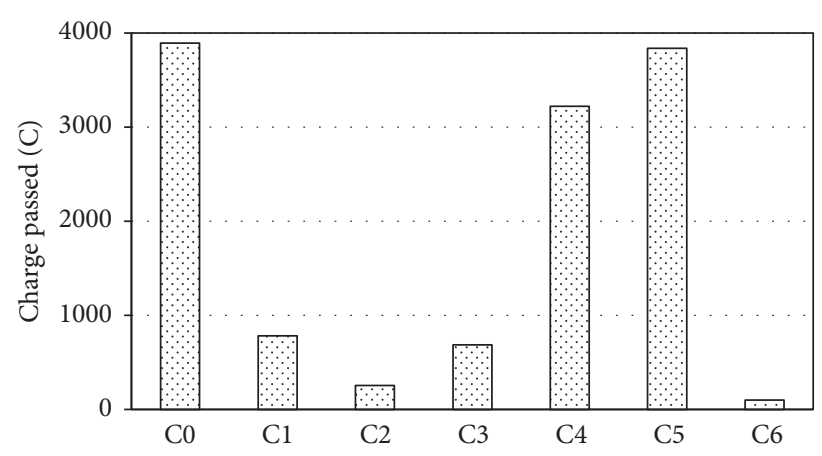

FIGURE 9: Charge passed for coated concrete samples.

and C6 were able to reduce the charge passed significantly. The results indicate that the specifically designed acrylicmodified coating, C6, had a very low permeability and could successfully prevent the penetration of the chlorides.

Freeze-thaw tests in the $7 \%$ sodium chloride solution (7\% instead of $4 \%$ was chosen to accelerate the penetration of chlorides through the coating) were conducted on the coated concrete samples. Figure 10 shows the relative dynamic modulus and the mass percentage of the scaled-off particles in the freeze-thaw test. As shown in Figure 10, the performance of surface coatings varied significantly. Overall, $\mathrm{Cl}$ and C6, which were the polymer-modified mortars, performed well as compared to other coatings. C6, as the specific-designed mortar, showed an even better performance. In Figure 10(b), the negative values mean the increase of the sample weight after the freeze-thaw cycles. The positive values imply the scaling off of the particles and the damage of the surface coating while the negative ones indicate that the surface coatings were not damaged and the moisture diffusion through the coating increased the sample weight. By comparing Figure 10(b) to Figures 9 and 10(a), it is found out that the intactness of the coating materials plays an important role in the penetration of the chloride ions into the concrete samples and the reduction of the relative dynamic moduli. In other words, the intactness of the coating implies a better performance of the coating material.

3.2.2. Application. The acrylic-modified cementitious coating in this study, C6, was applied to protect a corroded roadside structure in Xinjiang, as shown in Figure 11. The sequence of repairing the roadside structures was as follows:

(1) Clean and dry the surface of the corroded roadside structures and the rust of exposed rebars, if any.

(2) Paint the surface evenly with the freshly prepared acrylic-modified cementitious coating, C6. It is recommended to paint two or three times over the surface to reach a thickness of $3-5 \mathrm{~mm}$ of the coating.

(3) The coating has to be cured for one or two days after the painting to achieve its strength. During the curing, it is recommended to avoid the humid, raining, or cold weather condition.

As discussed in the previous paragraph, the intactness is important to the performance of the coating. Therefore, visual inspection, which is effective in detecting the cracking, was conducted to evaluate the intactness of the coating. Visual inspection in three years showed that the roadside structures are in good condition without obvious cracking. This result indicates the coating performed well. Currently, the coating material has been widely used in Xinjiang for the protection of highway roadside structures.

\section{Conclusions}

In this study, to improve the durability of the roadside structures of the highways in Xinjiang province, China, carboxylated styrene-butadiene latex modified concrete was recommended for the future construction of the roadside structures and acrylic latex modified mortar was suggested for the protection of the corroded roadside structures in Xinjiang. The durability of the polymer-modified concrete and coated concrete specimens was investigated through freeze-thaw tests, chloride ion permeability tests, and so forth. The following conclusions were drawn from this study:

(1) For the future construction of the roadside structures in Xinjiang, $0.013 \%$ of the air-entraining agent and $10 \%$ of the carboxylated styrene-butadiene latex are appropriate dosage rates for the modification of Portland cement concrete, considering the improvement of the freeze-thaw resistance, compressive strength, and chloride impermeability.

(2) The combined effect of the air-entraining agent and the carboxylated styrene-butadiene latex increased the volume of the pores with the size less than $100 \mathrm{~nm}$ but decreased that with the size larger than $100 \mathrm{~nm}$. Since the large capillaries (larger than $100 \mathrm{~nm}$ ) dominate the durability and strength of cementitious materials, the decrease of them implies the improvement of the overall durability. 


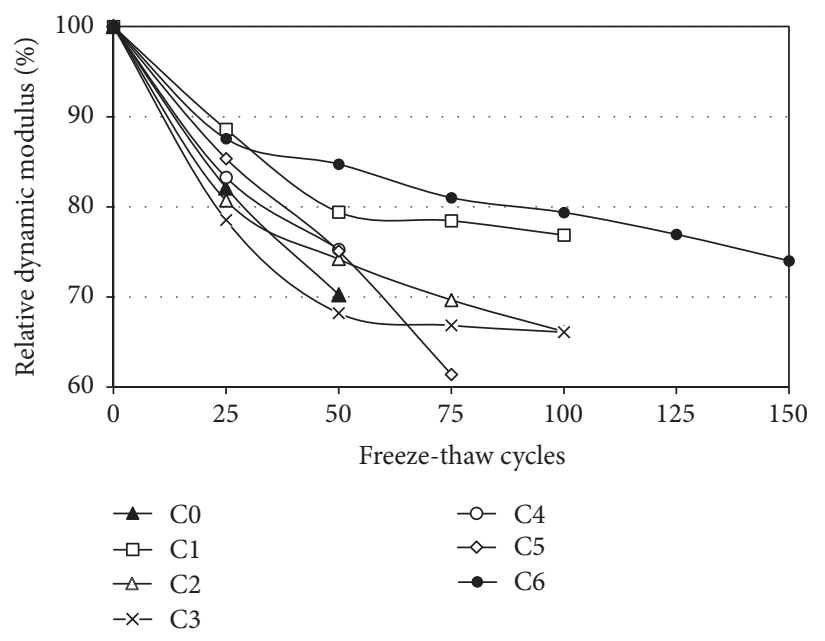

(a)

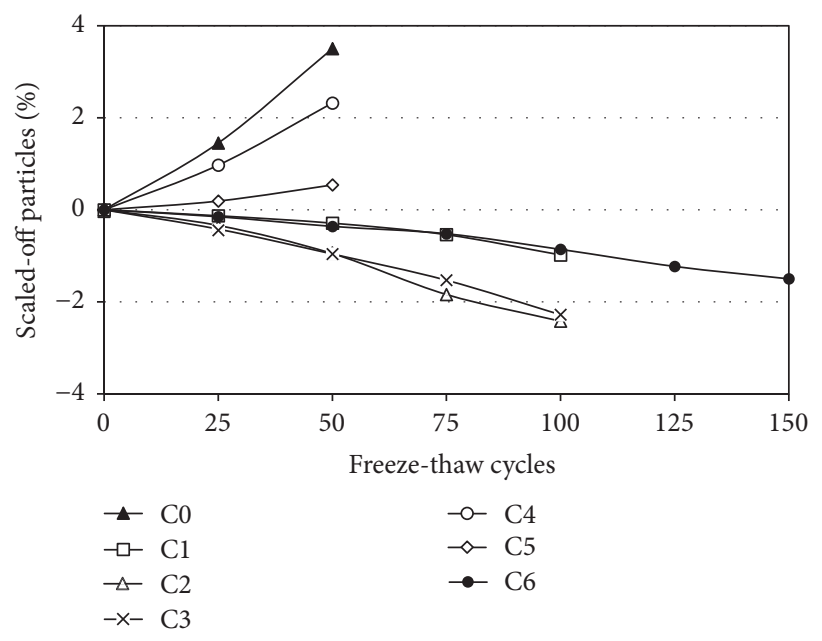

(b)

FIGURE 10: Coated concrete samples under freeze-thaw cycles: (a) relative dynamic modulus and (b) percentage of scaled-off mass.

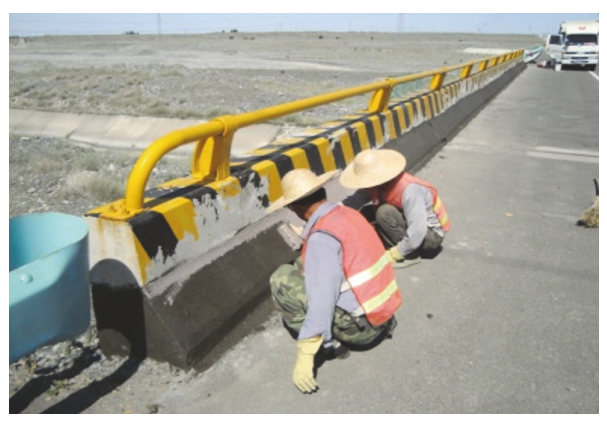

(a)

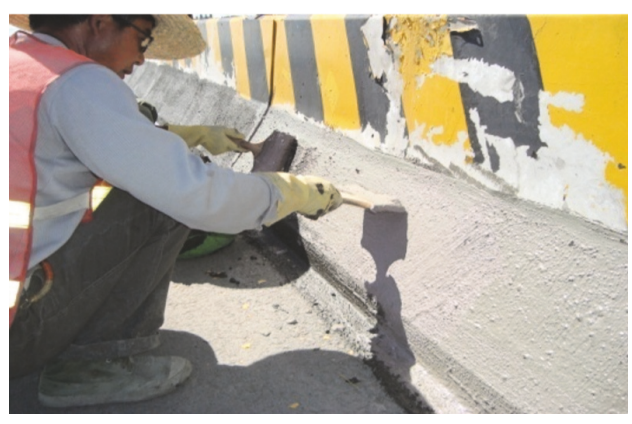

(b)

FIgURE 11: Paining of the acrylic-modified cementitious coating.

(3) For the protection of the current corroded roadside structures, the acrylic-modified cementitious coating material, C6, demonstrated the best performance. C6 was applied in a project in Xinjiang to protect a corroded highway roadside barrier and the three-year monitoring showed that the coating performed well in the field without obvious delamination or cracking.

\section{Disclosure}

Yinchuan Guo is currently a Visiting Scholar at Louisiana Transportation Research Center, 4101 Gourrier Avenue, Baton Rouge, LA 70808.

\section{Conflicts of Interest}

The authors declare that there are no conflicts of interest regarding the publication of this paper.

\section{Acknowledgments}

This study was supported by a grant from the National Natural Science Foundation of China (no. 51608047).

\section{References}

[1] P. C. Aitcin, "The durability characteristics of high performance concrete: a review," Cement and Concrete Composites, vol. 25, no. 4-5, pp. 409-420, 2003.

[2] M. L. Berndt, "Properties of sustainable concrete containing fly ash, slag and recycled concrete aggregate," Construction and Building Materials, vol. 23, no. 7, pp. 2606-2613, 2009.

[3] H. Figueiras, S. Nunes, J. S. Coutinho, and J. Figueiras, "Combined effect of two sustainable technologies: self-compacting concrete (SCC) and controlled permeability formwork (CPF)," Construction and Building Materials, vol. 23, no. 7, pp. 25182526, 2009

[4] A. Çolak, "Properties of plain and latex modified Portland cement pastes and concretes with and without superplasticizer," Cement and Concrete Research, vol. 35, no. 8, pp. 1510-1521, 2005.

[5] L. K. Aggarwal, P. C. Thapliyal, and S. R. Karade, "Properties of polymer-modified mortars using epoxy and acrylic emulsions," Construction and Building Materials, vol. 21, no. 2, pp. 379-383, 2007.

[6] P. J. M. Monteiro, A. P. Kirchheim, S. Chae et al., "Characterizing the nano and micro structure of concrete to improve its 
durability," Cement and Concrete Composites, vol. 31, no. 8, pp. 577-584, 2009.

[7] Z. Sun and Q. Xu, "Micromechanical analysis of polyacrylamide-modified concrete for improving strengths," Materials Science and Engineering A, vol. 490, no. 1-2, pp. 181-192, 2008.

[8] Z. Yang, X. Shi, A. T. Creighton, and M. M. Peterson, "Effect of styrene-butadiene rubber latex on the chloride permeability and microstructure of Portland cement mortar," Construction and Building Materials, vol. 23, no. 6, pp. 2283-2290, 2009.

[9] X. Wang, I. Rhee, Y. Wang, and Y. Xi, "Compressive strength, chloride permeability, and freeze-thaw resistance of MWNT concretes under different chemical treatments," The Scientific World Journal, vol. 2014, Article ID 572102, 8 pages, 2014.

[10] A. V. Girão, I. G. Richardson, C. B. Porteneuve, and R. M. D. Brydson, "Composition, morphology and nanostructure of C$\mathrm{S}-\mathrm{H}$ in white Portland cement pastes hydrated at $55^{\circ} \mathrm{C}$," Cement and Concrete Research, vol. 37, no. 12, pp. 1571-1582, 2007.

[11] T. Vidal, A. Castel, and R. François, "Corrosion process and structural performance of a 17 year old reinforced concrete beam stored in chloride environment," Cement and Concrete Research, vol. 37, no. 11, pp. 1551-1561, 2007.

[12] A. A. Almusallam, F. M. Khan, S. U. Dulaijan, and O. S. B. AlAmoudi, "Effectiveness of surface coatings in improving concrete durability," Cement and Concrete Composites, vol. 25, no. 4-5, pp. 473-481, 2003.

[13] W.-Y. Kuo, J.-S. Huang, and C.-H. Lin, "Effects of organomodified montmorillonite on strengths and permeability of cement mortars," Cement and Concrete Research, vol. 36, no. 5, pp. 886-895, 2006.

[14] H.-W. Song, S.-W. Pack, S.-H. Nam, J.-C. Jang, and V. Saraswathy, "Estimation of the permeability of silica fume cement concrete," Construction and Building Materials, vol. 24, no. 3, pp. 315-321, 2010.

[15] V. Slowik, T. Hübner, M. Schmidt, and B. Villmann, "Simulation of capillary shrinkage cracking in cement-like materials," Cement and Concrete Composites, vol. 31, no. 7, pp. 461-469, 2009.

[16] B. T. Tamtsia, J. J. Beaudoin, and J. Marchand, "The early age short-term creep of hardening cement paste: load-induced hydration effects," Cement and Concrete Composites, vol. 26, no. 5, pp. 481-489, 2004.

[17] P. Lura, O. M. Jensen, and K. V. Breugel, "Autogenous shrinkage in high-performance cement paste: an evaluation of basic mechanisms," Cement and Concrete Research, vol. 33, no. 2, pp. 223-232, 2003.

[18] Test methods of cement and concrete for highway engineering, JTG E30-2005, China Communications Press, 2005.

[19] "Corrosion prevention technical specifications for concrete structures of marine harbour engineering," JTJ 275-2000, China Communications Press, 2001.

[20] C. D. Atis, O. Karahan, K. Ari, Ö. C. Sola, and C. Bilim, "Relation between strength properties (flexural and compressive) and abrasion resistance of fiber (steel and polypropylene)-reinforced fly ash concrete," Journal of Materials in Civil Engineering, vol. 21, no. 8, pp. 402-408, 2009.

[21] S. Syachrani, H. S. Jeong, V. Rai, M. J. Chae, and T. Iseley, "A risk management approach to safety assessment of trenchless technologies for culvert rehabilitation," Tunnelling and Underground Space Technology, vol. 25, no. 6, pp. 681-688, 2010. 

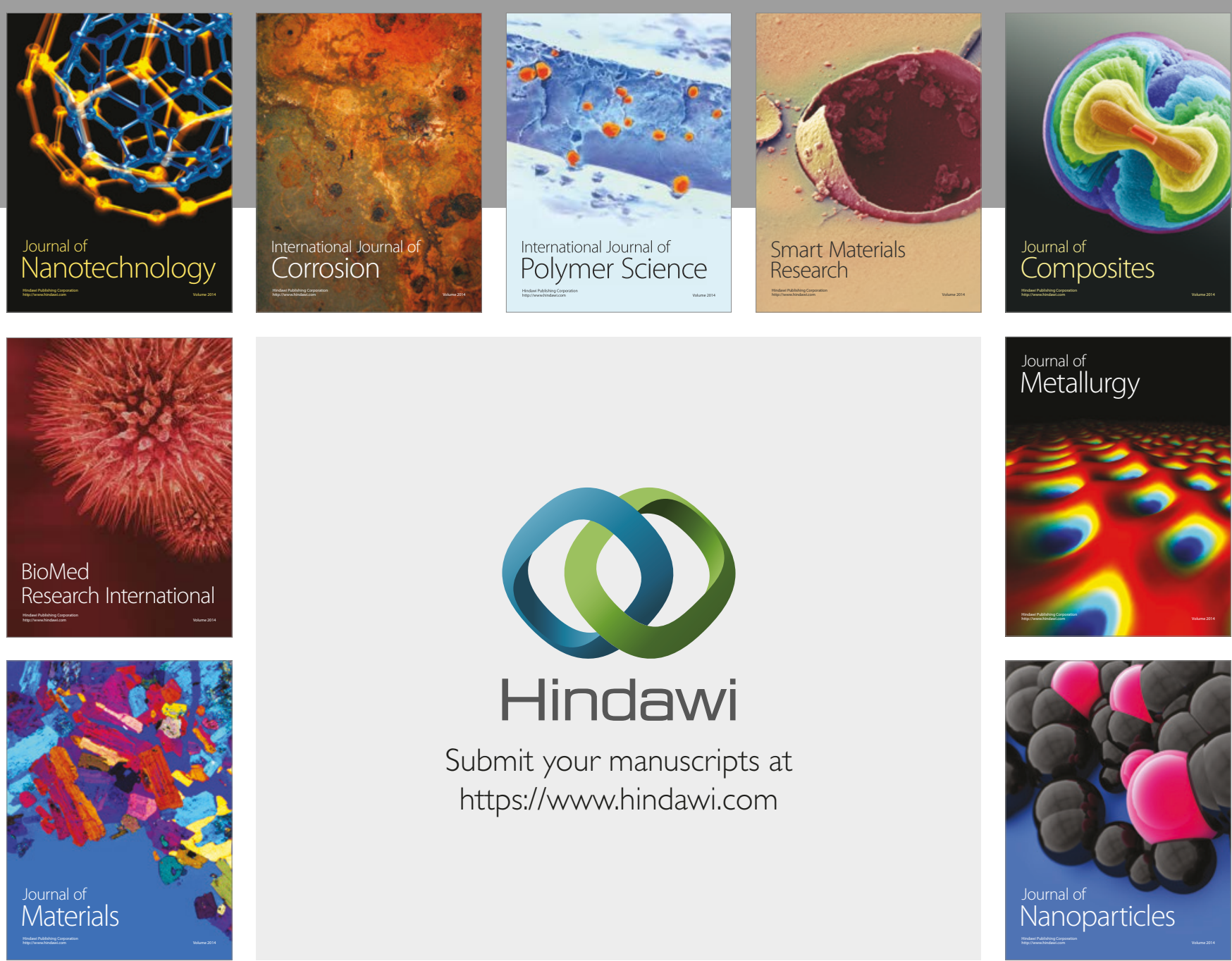

\section{Hindawi}

Submit your manuscripts at

https://www.hindawi.com
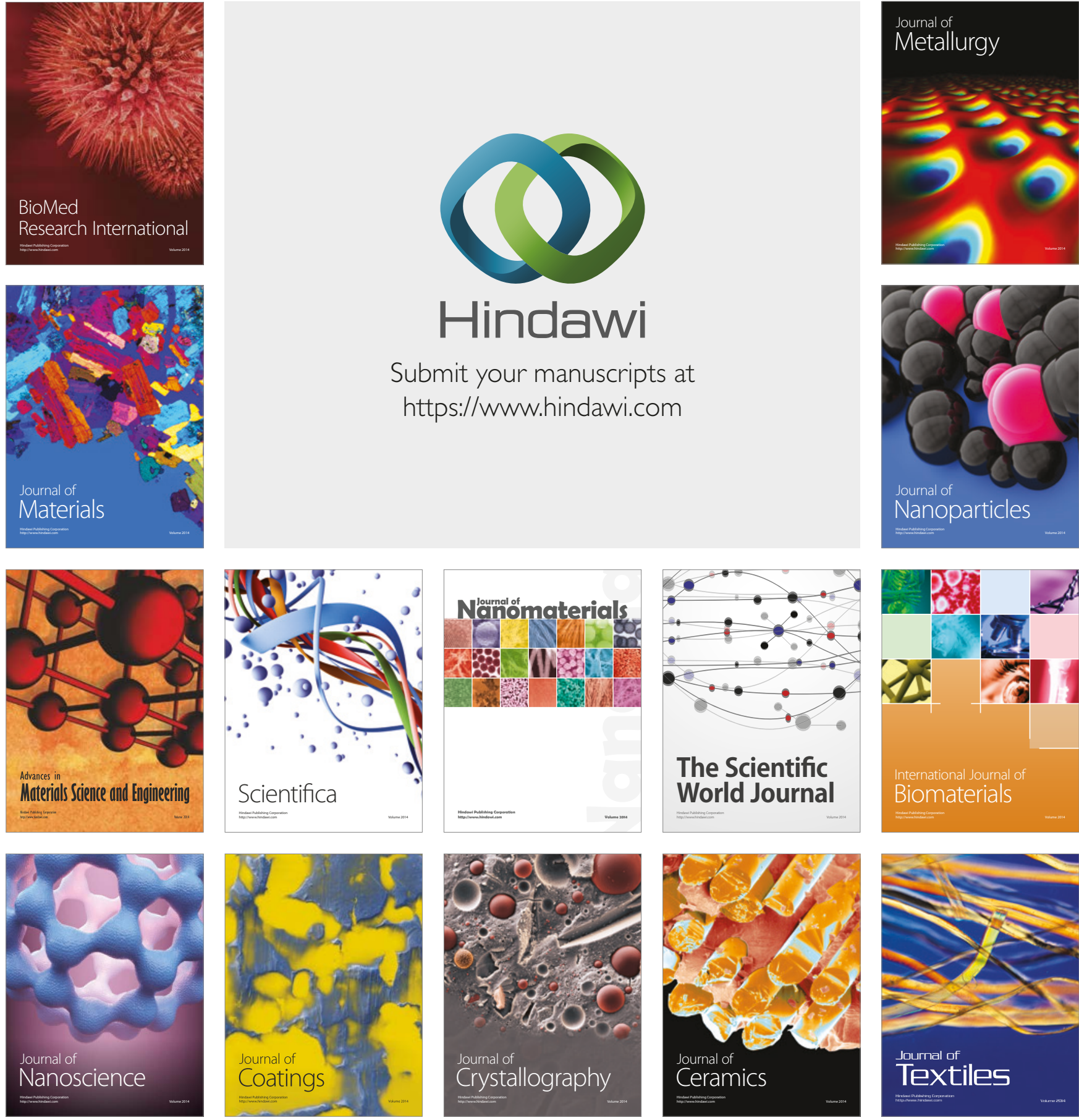

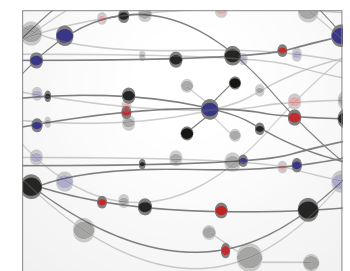

The Scientific World Journal
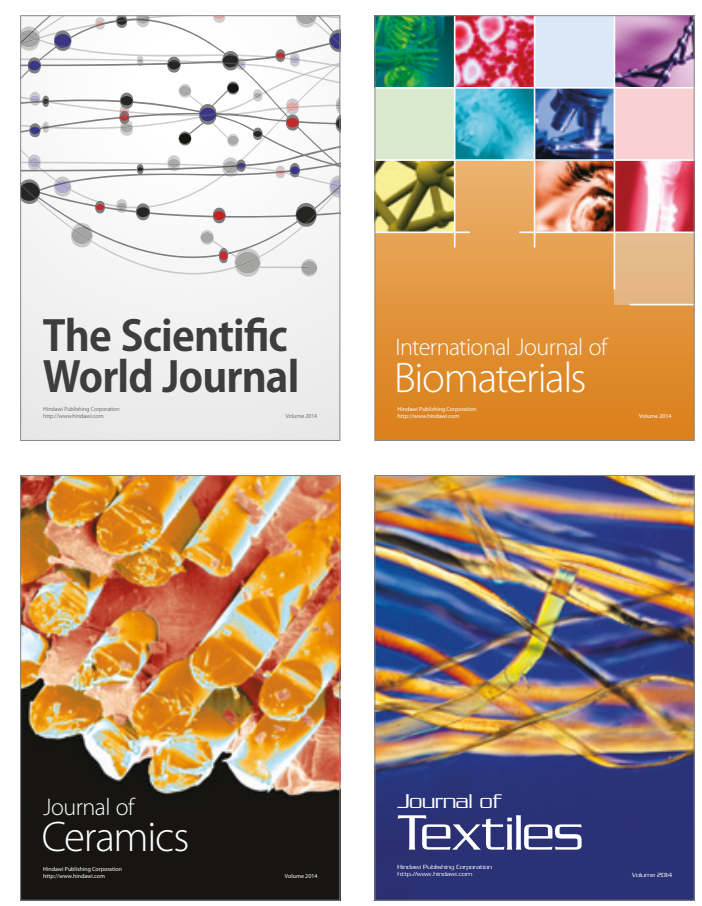